\title{
Degree of elaborative processing in two implicit and two explicit memory tasks
}

\author{
ALFONSO PITARQUE, SALVADOR ALGARABEL, and ENRIQUE MESEGUER \\ University of Valencia, Valencia, Spain
}

\begin{abstract}
The level of elaborative processing made by subjects to pairs of words (read vs. generated) and the degree of relationship between the words of each pair (related, rhymed, or rhymed and related) were manipulated on two explicit tasks (cued recall and recognition) and two implicit tasks (wordstem completion and tachistoscopic word identification) to test the empirical validity of the processing-approach theory (see, e.g., Roediger, 1990a, 1990b; Roediger, Srinivas, \& Weldon, 1989) of explicit/implicit dissociations. Results give support to the predictions made by Roediger's theory.
\end{abstract}

Explicit measures of memory, such as recall or recognition, reflect conscious recollection of past experiences, whereas implicit memory refers to memory for information expressed on tasks, such as priming, in which subjects are not required to consciously recollect episodic traces. That is why both types of task are also referred to, respectively, as conceptually driven and data-driven tests (see Richardson-Klavehn \& Bjork, 1988).

A variety of studies have shown experimental dissociations between implicit and explicit tasks in either neurological patients or normal subjects (see Roediger, 1990a, 1990b; Schacter, 1987, 1991, for reviews). Two main theoretical approaches have been used to explain these dissociations. As Roediger (1990b) states, researchers working in neuropsychological tradition prefer to postulate distinct memory systems, whereas most cognitive psychologists have proposed various processing approaches to explain the data.

One example of the first type of theory is that of Squire (1986, 1987; see also Schacter, 1989; Tulving, 1983, 1985), who makes a distinction between a declarative and a procedural memory system. The former could be related to verbal knowledge, being responsible for performance on explicit (or aware) tests, whereas the procedural system would be responsible for skilled behavior, priming, classical conditioning, and so forth, without the need for conscious recollection. Amnesic patients would have the declarative system damaged and would show poorer results on explicit tests than would normal subjects. However, as the procedural memory system is intact, their performance on implicit tests would be similar to that of normal subjects; this is the result usually found.

\footnotetext{
This research was supported by Grant PB88-0496 from Promoción General del Conocimiento de la Dirección General de Investigación Cientifica y Técnica del M.E.C. The authors want to express their thanks to M. T. Alarcón Frasquet, C. Bernal Santacreu, and M. D. Fernández Pascual for their help as lab assistants. Correspondence should be addressed to A. Pitarque, Universitat de Valencia, Facultat de Psicologia, Àrea de Metodologia, Avda. Blasco Ibáñez, 21, 46010 Valencia, Spain.
}

An alternative point of view is that many dissociations between explicit and implicit tasks could be explained by the different cognitive procedures required by the different types of tests (see Roediger, 1990a, 1990b; Roediger, Srinivas, \& Weldon, 1989). According to this theory, explicit and implicit tests usually access different forms of information and/or require different retrieval operations. As explicit tests rely on semantic or elaborative processing, they would have to be sensitive to conceptual manipulations. By contrast, implicit tests rely more on the match between perceptual operations between study and test phases and lead to alterations in performance with manipulations of the surface structure of information. Briefly, data-driven tests would be more sensitive to perceptual changes than would conceptually driven tests, whereas the latter would be more sensitive to meaning-based elaborations.

This experiment is in part a replication and in part a test of the predictions made by the transfer processing approach. Subjects had to read pairs of words (READ condition) or generate the second in relation to the first (GEN condition). Some of the words were semantically related (REL condition), others rhymed but were not related (RIM condition), and some others rhymed and were related (REL + RIM condition). The effects of such study-phase manipulations were tested on two explicit tasks (recognition and cued recall) and two implicit tasks (word-stem completion and tachistoscopic word identification).

In addition to the usual generation effect on implicit and explicit tasks, we expected that rhyming manipulation would induce better performance on explicit tasks when subjects had to look for meaningfully related words rather than rhymed words, and vice versa on implicit memory tasks.

\section{METHOD}

\footnotetext{
Subjects

The subjects were 125 Valencia University undergraduate psychology students, who participated in partial fulfillment of a course requirement.

Materials, Apparatus, and Procedure

Each subject was tested sequentially in a study phase, a distraction phase, and a test phase.
} 
Study phase. In the study phase, the subjects either read pairs of words (e.g., MOTHER-FATHER; READ condition) or generated the second stimulus in relation to the first, filling in the missing letter fragments to form legal words as in a word-fragment completion task (see Tulving, Schacter, \& Stark, 1982; e.g., MOTHER-F_TH_R; GEN condition).

In both cases, 45 pairs of stimuli were presented. Each stimulus set was composed of three different subgroups. In 15 trials, the second stimulus (or target) was a word nonsemantically related but rhymed with the first word of the pair (e.g., TREASON-REASON Or TREASON-R_ASO_, depending on whether the subject had to read or generate the target; RIM condition). In another 15 trials, the target was related to the first stimulus but did not rhyme (e.g., TRIAL-JUDGE or TRIAL-J_D_E; REL condition). The remaining stimuli were pairs of words related and rhymed (e.g., CAPACITY-ABILITY Or CAPACITY-AB_LIT_; REL + RIM condition). The order in which the three sets were presented to the subjects was counterbalanced randomly within subjects.

A computer program assigned a different set of words to each subject. That is, from a set of 60 four-word chains (e.g., MOTHER-FATHERDAUGHTER-MURDER, where the second word is rhymed and related to the first one, the third is related but not rhymed, and the fourth rhymed but was not related), the program first randomly selected the 45 chains that would compose one individual file and then, keeping constant the first word, randomly selected the second stimuli of the pair, assigning it to the RIM condition, the REL condition, or the REL + RIM condition. All words were between 5 and 10 letters long, and all had a medium frequency. Target words used in the GEN condition target were made by randomly replacing letters with blanks. Two blanks were used if the word was 5 or 6 letters long, three blanks were used if the word was 7 or 8 letters long, and four blanks were used in the remaining cases. In a GEN pilot test, we verified that only one valid solution was possible for each target stimulus.

Trials were presented on the screen of an Apple Macintosh Plus. In the READ condition, the subjects were instructed to read the target word aloud, whereas in the GEN condition, the subjects were instructed to produce the target in relation to the first word. The subjects were given six practice trials prior to the study task, and were limited to $10 \mathrm{sec}$ to answer. When the answer was wrong, an experimenter, who was sitting beside the subject, read the correct answer out loud.

Distraction phase. In a pencil-and-paper distraction task, the subjects were instructed to fill gaps in letter chains such as "ARG_NT_NA_UEN_S A_RES," that is, relating nations and their capital cities, for $3 \mathrm{~min}$.

Test phase. Each subject was randomly assigned to one of the following four tasks:

Cued recall. Ninety words were sequentially presented on the computer screen for no more than $10 \mathrm{sec}$ each; 45 of them were the first of each pair of words read or generated in the study phase. The remaining words were fillers. The subjects were instructed to use the first word as a cue to remember the target from the first part of the experiment. Twenty-two subjects were assigned to perform this task

Recognition. As in the cued-recall task, 90 words (the 45 studied targets and 45 fillers) were presented. The 32 subjects were instructed to identify the word as "new" or "old."

Word-stem completion. Forty-five three-letter stems (e.g., FAT-__) were presented; the subjects had to produce, as quickly as possible, the first word that came to mind beginning with the same stem as the target. The three-letter stems of each of the target words had to be represented by at least 10 Spanish words in a pocket dictionary, and all the stems had to be unique in the set of all words used for the experiment (Graf \& Schacter, 1985). Such stems were the three initial letters of the targets that appeared in the study phase. Thirty-two subjects were assigned to perform this task.

Tachistoscopic word identification. In a pilot phase of the present experiment, we had conducted an investigation to determine individual perceptual thresholds: We presented 50 masked words (five blocks of 10 words each), and manipulated the exposure time of the words in an increasing order (the exposure times were $33 \mathrm{msec}$ for the first 10 words, $50 \mathrm{msec}$ for the next 10 , and 67,83 , and $100 \mathrm{msec}$, respectively, for the third, fourth, and fifth blocks). The subjects were told to try to identify these words, and the threshold was set at the time needed by each sub- ject to identify $50 \%$ of the words. In the present identification task, 90 masked words (the $\mathbf{4 5}$ studied targets and $\mathbf{4 5}$ filler words used during recognition) were presented. The subjects were told to try to identify these words and to read them aloud. Thirty-nine subjects were assigned to perform this task.

\section{RESULTS AND DISCUSSION}

First, and prior to any analysis, mean proportions of correctly generated words in the REL + RIM, RIM, and REL conditions were analyzed by an analysis of variance (ANOVA). The main effect of type of relatedness was significant $\left[F(2,124)=42.57, M S_{\mathrm{e}}=.01, p<.0001\right]$. The REL + RIM target words $(M=.92)$ were better generated than were REL words $(M=.87, p<.05)$, which in turn were better generated than RIM-condition words $(M=.75, p<.01)$. As we expected, this fact guarantees a different level of processing for each generated condition.

Then, four $2 \times 3$ mixed ANOVAs (type of study task, between subjects: generated vs. read; type of relatedness within pairs, within subjects: REL, RIM, REL + RIM) were performed on the data from each test task.

\section{Cued-Recall Task}

Results from a $2 \times 3$ ANOVA performed on the mean proportions of recalled words showed a significant main effect of type of study test $\left[F(1,20)=9.79, M S_{\mathrm{e}}=0.03\right.$, $p=.005]$, type of relatedness $\left[F(2,40)=41.29, M S_{\mathrm{e}}\right.$ $=.014, p=.0001]$, and their interaction $[F(2,40)=$ $6.62, M S_{\mathrm{e}}=.014, p=.003$ ]. The GEN words were better recalled than were the READ words $(M s=.38$ and .24 , respectively). A post hoc Newman-Keuls analysis showed that the RIM + REL and REL conditions were better recalled than was the RIM condition $(.43, .38$, and .12 , respectively), in spite of there being no difference between the two former conditions. Figure 1 shows the interaction. A simple post hoc analysis showed significant effects of all variables $(p<.01)$, except for the effect of type of study task in the RIM condition.

These results clearly support the predictions made by the processing-approach theory in the sense that conceptually driven tests are sensitive to meaning-based elaborations.

\section{Recognition Task}

Results on the mean proportions of recognized words were very similar to the results found in the former explicit task. Type of study test $\left[F(1,30)=9.4, M S_{\mathrm{e}}=0.03\right.$, $p=.005]$ and type of relatedness $\left[F(2,60)=7.78, M S_{\mathrm{e}}\right.$ $=.01, p=.001]$ were significant, while their interaction was marginally significant $\left[F(2,60)=2.71, M S_{\mathrm{e}}=.01\right.$, $p=.075]$. As before, GEN words were better recognized than were READ words (.84 and .73 , respectively). A post hoc Newman-Keuls analysis showed that the RIM + REL and REL conditions were better recognized than was the RIM condition (.81, .81, and .73, respectively). Figure 1 shows the interaction. A simple post hoc analysis showed significant effects of all variables $(p<.01)$, except for 

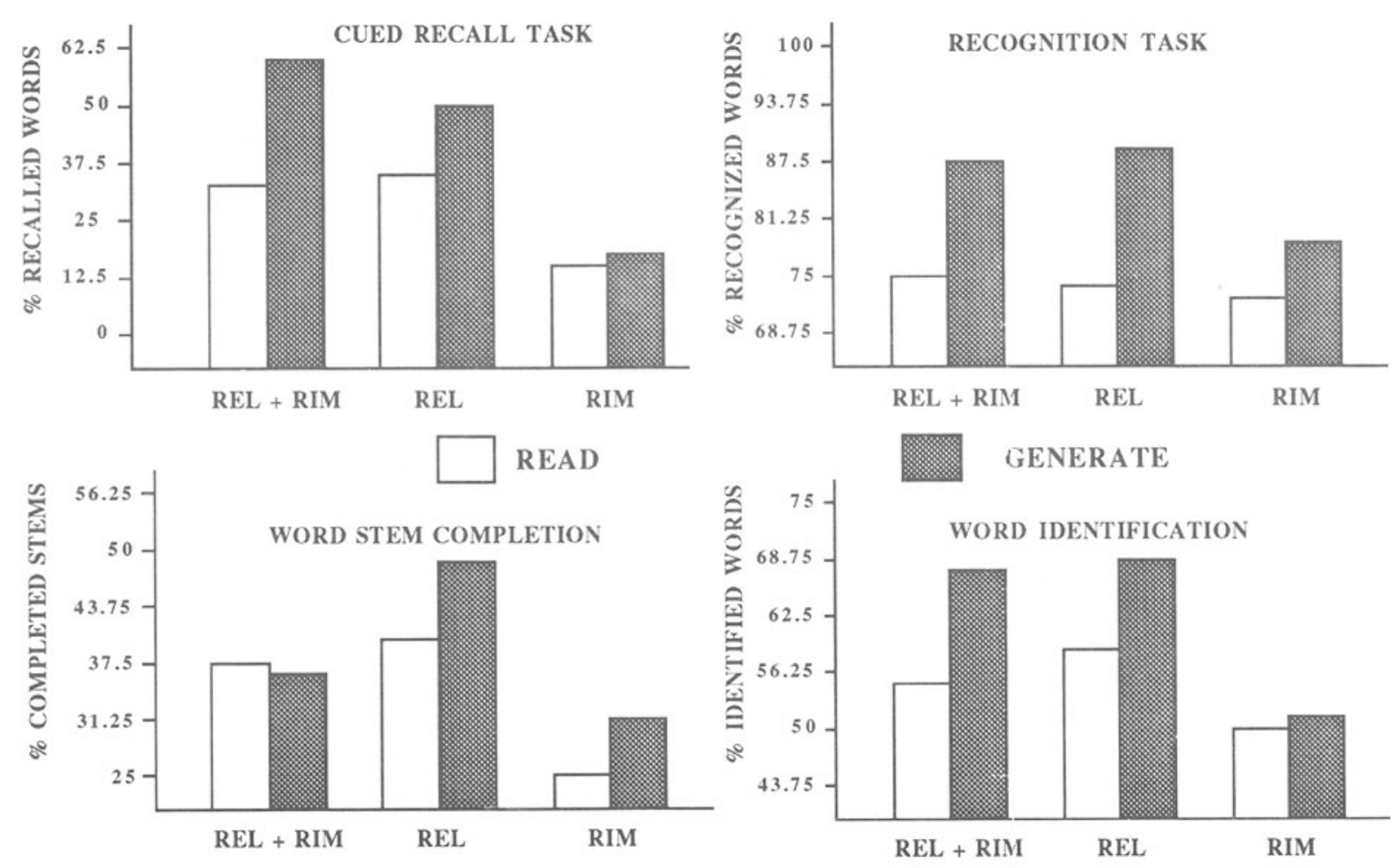

STUDY CONDITIONS

Figure 1. Percentage of correct responses as a function of study condition and type of task.

the effect of type of study task in the RIM condition and the effect of type of relatedness in the READ condition.

\section{Word-Stem Completion}

An $2 \times 3$ mixed ANOVA performed on the mean proportions of words produced in the same way as the target items from the study list showed that only the main effect of type of relatedness was significant $\left[F(2,60)=16.54, M S_{\mathrm{e}}\right.$ $=.01, p=.0001]$. A post hoc Newman-Keuls analysis showed that the REL condition $(M=.44)$ was better completed $(p<.05)$ than was the REL + RIM condition $(.35)$, which in turn was better completed than was the RIM condition (.28). Figure 1 shows the interaction of type of study task by type of relatedness within pairs.

These results indicate that the word-stem completion task is not as sensitive to elaborative processing (read vs. generated) as the processing-approach theory would predict, whereas the results coming from the variable "type of relatedness within pairs" show the typical semantic priming effect that can occur in a clear, implicit way (see, e.g., Forster, Booker, Schacter, \& Davis, 1990).

\section{Tachistoscopic Word Identification}

Data of subjects for whom mean proportion of identified filler words was less than .25 or more than .75 were previously rejected from analysis. This shows that the perceptual threshold of these subjects was not correctly found. Accordingly, data from 13 subjects (33\% of the subjects assigned to perform this task) were rejected.

Results on the mean proportions of identified words were very similar to the results found in the former implicit task, showing as significant only the main effect of type of relatedness $\left[F(2,48)=11.8, M S_{\mathrm{e}}=.01, p=\right.$ $.0001]$. A post hoc Newman-Keuls analysis showed that the REL and REL + RIM conditions $(M s=.63$ and .60 , respectively) were better identified than was the RIM condition $(M=.49)$, in spite of there being no difference between the two former conditions. Figure 1 shows the interaction of type of study task by type of relatedness within pairs.

Approaching these data in a global sense, the results from the four tasks seem to support both the explicit/ implicit distinction made by Schacter and his colleagues (manipulated variables seem to similarly affect the two explicit tasks, but to differentially affect the two implicit tasks and the predictions made by the processing-approach theory (Roediger et al., 1989) in the sense that data-driven tests seem not to be sensitive to meaning-based elaborations, whereas explicit tests do (see also Blaxton, 1989, Experiment 1). 


\section{REFERENCES}

Blaxton, T. A. (1989). Investigating dissociations among memory measures: Support for a transfer appropriate processing framework. Journal of Experimental Psychology: Learning, Memory, \& Cognition, 15, 657-668.

Forster, K., BoOKer, J., Schacter, D. L., \& DAvis, C. (1990). Masked repetition priming: Lexical activation or novel memory trace? Bulletin of the Psychonomic Society, 28, 341-345.

Graf, P., SChacter, D. L. (1985). Implicit and explicit memory for new associations in normal and amnesic subjects. Journal of Experimental Psychology: Learning, Memory, \& Cognition, 11, 501-518.

Richardon-KLavehn, A., \& Bjork, R. A. (1988). Measures of memory. Annual Review of Psychology, 39, 475-543.

RoEDIGER, H. L., III (1990a). Implicit memory: A commentary. Bulletin of the Psychonomic Society, 28, 373-380.

ROEDIGER, H. L. (1990b). Implicit memory: Retention without remembering. American Psychologist, 45, 1043-1056.

Roediger, H. L., Srinivas, K., \& Weldon, M. S. (1989). Dissociations between implicit measures of retention. In $\mathbf{S}$. Lewandowsky, J. C. Dunn, \& K. Kirsner (Eds.), Implicit memory: Theoretical issues (pp. 67-84). Hillsdale, NJ: Erlbaum.

SCHACTER, D. L. (1987). Implicit memory: History and current status. Journal of Experimental Psychology: Learning, Memory, \& Cognition, 13, 501-518.
SCHACTER, D. L. (1989). On the relation between memory and consciousness: Dissociable interactions and conscious experience. In $\mathrm{H}$. L. Roediger \& F. I. M. Craik (Eds.), Varieties of memory and consciousness: Essays in honor of Endel Tulving (pp. 355-389). Hillsdale, NJ: Erlbaum.

SCHACTER, D. L. (1991). Perceptual representation systems and implicit memory: Toward a resolution of the multiple system debate. In A. Diamond (Ed.), The development and neural basis of higher cognitive function. New York: New York Academy of Sciences Press.

SQUIRE, L. R. (1986). Mechanisms of memory. Science, 232, 1612-1619.

SQUIRE, L. R. (1987). Memory and brain. New York: Oxford University Press.

Tulving, E. (1983). Elements of episodic memory. Oxford: Oxford University Press.

Tulving, E. (1985). How many memory systems are there? American Psychologist, 40, 385-398.

Tulving, E., Schacter, D. L., \& Stark, H. D. (1982). Priming effects in word-fragment completion are independent of recognition memory. Journal of Experimental Psychology: Learning, Memory, \& Cognition, 8, 336-342.

(Manuscript received November 30, 1991.)

\section{Call for Assistance in The Compilation of a History of the Psychonomic Society}

The Governing Board of the Psychonomic Society is pleased to announce that Robert C. Bolles has agreed to serve as the first Historian of the Society.

All members who might have information relevant to this undertaking are invited to send it directly to Dr. Bolles. Founding members and those who attended the early meetings are especially encouraged to record their reminiscences. While Dr. Bolles hopes to collect as much information as possible relevant to the history of the Society, he will concentrate first on the early history.

Dr. Bolles's address is Department of Psychology, University of Washington, Seattle, Washington 98195 (phone: 206-543-2631). 